\title{
Traumatismo dentário com sucesso no reimplante - um relato de caso
}

\section{Dental traumatism with successive reimplant: a case report}

\begin{abstract}
RESUMO
Avulsão dentária está relacionada com causas extrínsecas como acidentes e violência. Tendo alta incidência em crianças de 7-12 anos, sendo os incisivos centrais superiores os dentes mais acometidos. Paciente YD, 9 anos de idade, gênero masculino, buscou atendimento na clínica infantil/UMESP acompanhado da mãe com queixa principal de estética/emocional decorrente da perda do elemento 21 e extrusão do 11 após queda de bicicleta. Imediatamente após queda, a criança foi para Santa Casa onde realizaram contenção do elemento 11, porém não houve reimplante do 21 , pois este foi perdido. Ao exame clínico, foi observada extrusão e infra-oclusão de aproximadamente $4 \mathrm{~mm}$ do elemento 11 e intrusão dos elementos 12 e 22 . Foi realizada radiografia periapical modificada anterior superior para analisar a situação periodontal e integrar plano de tratamento. A contenção foi removida, observando uma mobilidade no 11. Confeccionou-se aparelho removível superior estético com alças para intrusão. Utilizou-se elástico de 3/16" leve, com 20gF, para intrusão do 11 até a altura do provisório 21. Em 15 dias observou-se que o dente estava quase reposicionado, faltando apenas $1 \mathrm{~mm}$ para alcançar a altura correta e não havia mobilidade. Foi diagnosticada necrose do elemento 11, após o teste de vitalidade, provavelmente devido ao trauma. Desse modo, o mesmo foi encaminhado para avaliação endodôntica. A intrusão do 11 ocorreu com sucesso e, até que o paciente tenha idade suficiente para realização do implante do 21 , deverá ser mantido aparelho estético/funcional ou contenção.
\end{abstract}

Palavras chave: Odontopediatria. Mantenedor de espaço em Ortodontia. Traumatismos Dentários.

\begin{abstract}
Dental avulsion is related to extrinsic causes such as accidents and violence. With a high incidence in children aged 7-12 years, the central incisors being the most affected teeth. Patient YD, 9 years old, male, sought care in the children's clinic / UMESP accompanied by the mother with aesthetic/ emotional complaint due to the loss of element 21 and extrusion of 11 after a bicycle fall. It was reported that immediately after falling, the child went to Santa Casa, where they carried out containment of element 11, but there was no reimplantation of 21, since it was lost. At the clinical examination, it was observed extrusion and infraocclusion of approximately $4 \mathrm{~mm}$ of element 11 and intrusion of elements 12 and 22. A previous upper modified periapical radiography was performed to analyze the periodontal situation and integrate treatment plan. The containment was removed, observing a mobility in the 11. Aesthetic upper removable apparatus with intrusion handles was made. A light $3 / 16$ "elastic was used, with $20 \mathrm{gF}$, for intrusion of 11 to the height of provisional 21. In 15 days it was observed that the tooth was almost repositioned, missing only $1 \mathrm{~mm}$ to reach the correct height and there was no mobility. Element 11 necrosis was diagnosed after the vitality test, probably due to trauma. Thus, it was referred for endodontic evaluation. Intrusion of 11 occurred successfully and, until the patient is old enough to perform the 21 implant, an aesthetic / functional device or restraint should be maintained.
\end{abstract}

Key-words: Pediatric dentistry. Tooth Injuries. Space Maintenance. Orthodontic.

\section{Gabriela Escóssia de Figueiredo ${ }^{1}$ André Luis Ribeiro de Miranda ${ }^{2}$ Maria Cristina Duarte Ferreira ${ }^{3}$ Sonia Maria de Lima ${ }^{4}$ Renato Morales Jóias ${ }^{3}$ Renata Pilli Jóias ${ }^{4}$}

${ }^{1}$ DDS. Aluna do Curso de Odontologia, Universidade Metodista de São Paulo ${ }^{2}$ DDS, MsC, PhD. Consultório particular ${ }^{3}$ DDS, MsC, PhD. Professor do Curso de Odontologia, Universidade Metodista de São Paulo ${ }^{4}$ DDS, MsC, PhD. Professora do Curso de Odontologia e do Curso de Especialização em Ortodontia, Universidade Metodista de São Paulo

Autor para correspondência: Gabriela Escóssia de Figueiredo Rua Avenida jardim Japão, 690 casa 03. SP E-mail: gabiescossia17@gmail.com Tel (11) 974731259. 


\section{INTRO DUÇÃO}

O traumatismo alvéolo-dentário corresponde a um conjunto de impactos que afeta os dentes e suas estruturas de suporte; por sua vez, a avulsão dentária caracteriza-se pelo total deslocamento do dente para fora do alvéolo e, diante de tal situação, recomenda-se o imediato reimplante dental ${ }^{1}$. Sua maior prevalência é em jovens com idade escolar, tendo como etiologia: quedas, quedas de bicicleta, atropelamento, acidentes automobilísticos, agressões e prática de esportes ${ }^{2-3}$. A maior incidência das avulsões está associada aos incisivos centrais superiores permamentes, em crianças de 7-12 anos de idade, em razão das atividades de infância e da adolescência, favorecendo a exposição dos traumas dentais, além da menor quantidade de fibras do ligamento periodontal do dente recém erupcionado e da rizogênese incompleta ${ }^{1-3}$.

Em relação ao gênero, a literatura tem mostrado que os meninos são os mais acometidos, aproximadamente duas vezes mais do que as meninas, sendo 30 e 16,1\% respectivamente ${ }^{3-5}$. Crianças do gênero masculino, hiperativas, apresentando overjet superior a $5 \mathrm{~mm}$ e selamento labial inadequado, tem maior predisposição ao trauma dentário ${ }^{3,6-7}$. Uma vez ocorrida a avulsão dentária, a vitalidade do ligamento periodontal é fator de grande importância para o sucesso do reimplante do dente avulsionado, recomendando-se, diante da impossibilidade do reimplante imediato, que o mesmo seja armazenado em meio úmido, nunca em meio seco ${ }^{1-3,8-9}$.

Vários meios de armazenamento foram citados nas pesquisas, dentre eles: Solução Salina Balanceada de Hanks (SSBH), sangue, saliva, leite, vestíbulo bucal e meios de cultura. Dos meios citados, segundo as pesquisas de Hiltz e Trope, o de eleição seria SSBH, porque ela não oferece alteração morfológica, nem altera a capacidade mitótica das células, podendo então manter $70 \%$ dos fibroblastos vitais por 96 horas; sendo que no leite os fibroblastos são mantidos vivos, mas com alterações morfológicas. Leite é o segundo mais indicado, quando houver a ausência da SSBH. Seu armazenamento é por até 6 horas $^{5-12}$. A saliva por ser um meio contaminado, não sendo indicado, porque bactérias podem adentrar no elemento pelas microfissuras da superfície dentária, permitindo a contaminação bacteriana pulpar e o estabelecimento da reabsorção radicular externa inflamatória9,13-14. Água é a última alternativa, devendo ser usada para armazenar dentes avulsionados, apenas quando os outros meios citados estiverem inacessíveis ${ }^{14}$. A avulsão dentária não consiste apenas em danos ao ligamento periodontal, mas também na vascularização, responsável pela nutrição e oxigênio às células do dente. O dano é proporcional à intensidade e duração do trauma e ao estágio de desenvolvimento radicular. Quando há muita demora no reimplante, pode ocorrer necrose e inflamação nos tecidos envolvidos e, tardiamente, anquilose e reabsorção radicular. Quando há cicatrização, observa-se revascularização do ligamento periodontal, união das fibras de Sharpey rompidas, formação de uma nova adesão gengival e por fim, revascularização e reinervação da polpa ${ }^{1}$.

Fator muito importante para que o reimplante tenha sucesso é o tempo extraoral do elemento, que quanto menor, melhor. A necessidade de terapia endodôntica depende do tempo extraoral e do estágio de desenvolvimento radicular ${ }^{9,15}$. Em dentes com rizogênese completa, reimplantados, não se pode esperar que ocorra revascularização e 
o tratamento endodôntico deverá ser executado 7-10 dias após o traumatismo a fim de impedir novos danos ao ligamento periodontal e/ou o desenvolvimento da reabsorção radicular do tipo inflamatória. Recomenda-se a extirpação pulpar e preenchimento do canal radicular com uma pasta de hidróxido de cálcio (curativo de demora), sendo que a obturação com guta-percha não deverá ser realizada até que uma lâmina dura intacta possa ser detectada radiograficamente ${ }^{1,14}$. Em dentes com rizogênese incompleta com tempo menor que 60 minutos fora da boca, pode ter a revascularização. Antes do reimplante o elemento deve ser imerso em solução com clorexidina 5 minutos antes do procedimento. No caso de dentes avulsionados com rizogênese completa e permanecidos em um meio seco extraoral por um período superior a 60 minutos, o tratamento de escolha consiste na remoção do ligamento periodontal e tratamento da superfície radicular por meio de substâncias químicas, antes do reimplante ${ }^{14}$. Acompanhamento radiográfico é indispensável durante 4 semanas após o trauma, pois nele evidenciará alteração patológica, necessitando então de tratamento endodôntico. Após o reimplante do dente avulsionado, recomenda-se, preferencialmente, a estabilização deste através da esplintagem semirrígida com fio de nylon e resina composta ou outro similar, por um período de 7 a 14 dias. Essa contenção favorecerá a cicatrização pulpar e periodontal, bem como a estabilização dentária durante o período de cicatrização. Além disso, deverá ser feita uma análise criteriosa da extensão da esplintagem, pois muitas vezes os dentes adjacentes possuem algum tipo de trauma associado ${ }^{16}$. O melhor mantenedor de espaço é o próprio dente, por isso o papel do dentista é tentar mantê-lo na boca, mas quando não é possível, é recomendado o uso de mantenedor fixo ou móvel, que ajudará na estética, como por exemplo para que o paciente não fique com o dente ausente até chegar na maioridade e também ele podem evitar os hábitos deletéricos: interposição lingual, deglutição atípica e desequilíbrio oclusal. Dessa maneira, o objetivo desse relato de caso foi relatar as formas adequadas de tratamento, conduta dos responsáveis e profissionais para que haja sucesso no reimplante, com o auxílio de mecanismos como aparelhos expansores, que substituindo os dentes perdidos precocemente terão extrema importância ao evitar problemas na dentição mista ou permanente.

\section{RELATO DE CASO}

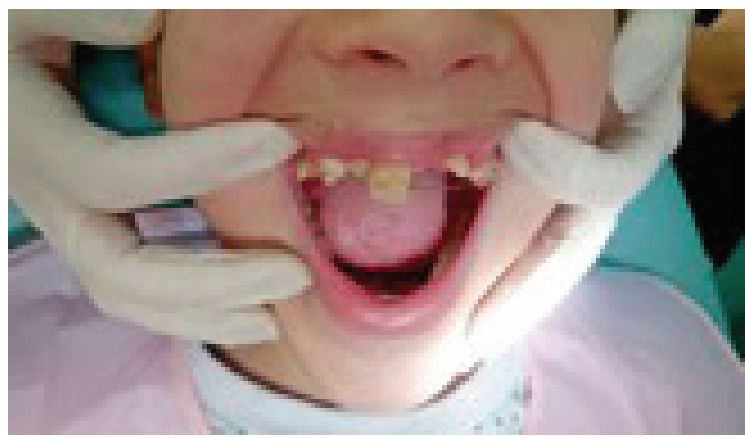

Figura 1 - Contenção com ausência do elemento 21.
O paciente YD, 9 anos de idade, sexo masculino, compareceu na clínica da Universidade Metodista de São Paulo acompanhado de sua mãe, após dois meses após ter caído da bicicleta e ter traumatizado a região de incisivos superiores (figura 1). A queixa principal da mãe era a ausência do dente 21 , que estava afetando psicologicamente o paciente, inclusive deixando-o constrangido no ambiente escolar. 


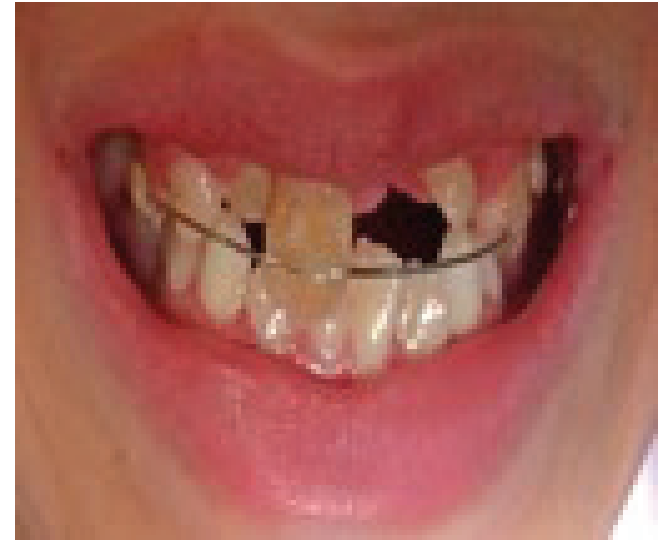

Figura 2 - Contenção rígida feita no hospital Santa Casa.

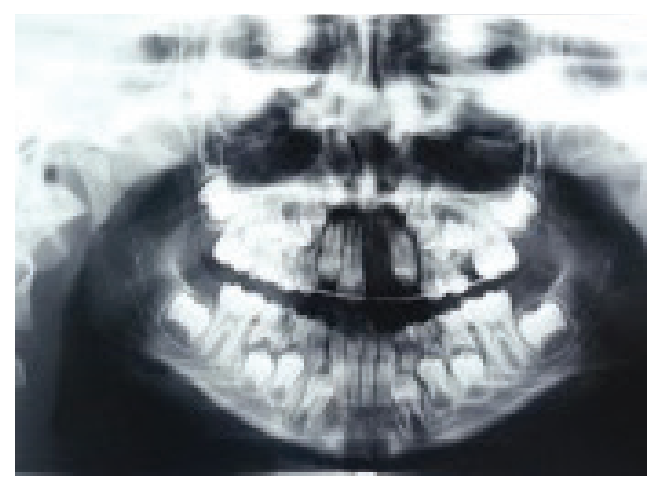

Figura 3 - Exame radiográfico panorâmico.

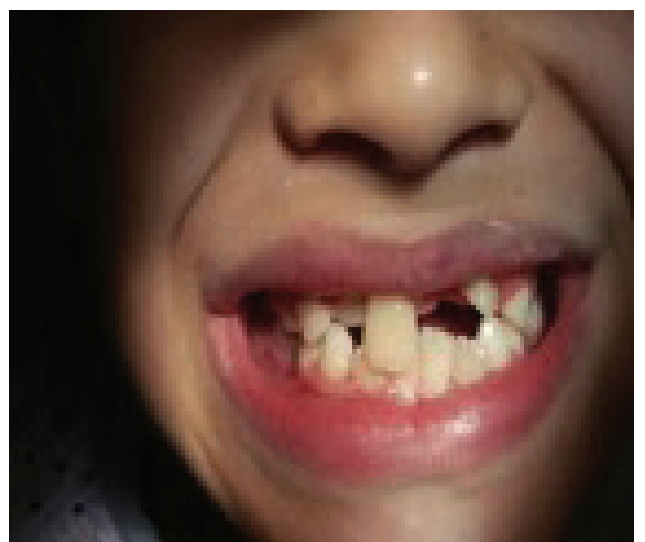

Figura 4 - Após a retirada da contenção.
O serviço de resgate foi chamado imediatamente e o garoto foi levado para a Santa Casa, onde fizeram a contenção do elemento 11 que ficou mais de um mês instalada (figura 2). Não houve reimplante do 21, pois este foi perdido)

A responsável relatou que o filho não possuía nenhuma doença sistêmica. No exame clínico foi visto: elemento 11 extruído, os laterais 12 e 22 intruídos e o 21 avulsionado (que não foi encontrado). Foram feitas radiografias periapicais anterior superior, com a finalidade de averiguar a situação periodontal dos dentes afetados no acidente e auxiliar no plano de tratamento. Observou-se que o elemento 11 estava com infra-oclusão de aproximadamente $4 \mathrm{~mm}$ (figura 3 ).

Foi visto que havia necessidade de utilizar-se aparelho móvel, o qual reposicionaria o 11, bem como teria a função de provisório para o dente 21 até o paciente ter idade para colocação de implante. Foi removida a contenção, os arcos superior e inferior foram moldados e foi feito um planejamento de um aparelho removível com parafuso expansor superior, arco de Hawley e levantamento de mordida, que foi ajustado semanalmente com $2 / 4$ de volta. Associado a esse, foi necessário o uso de um elástico de 3/6 leve, a $20 \mathrm{gF}$, que envolvia o dente 11 para que este intruísse e chegasse à altura do provisório 21 (figuras 4 e 5).

O movimento foi muito cuidadoso devido ao alvéolo estava lacerado, então sempre houve acompanhamento radiográfico e aferição do elástico para que o dente não intruísse descontroladamente. Em 15 dias o dente estava praticamente reposicionado (figuras 6 e 7).

Embora o paciente não tivesse sintomatologia, após o teste térmico, foi diagnosticada necrose do elemento 11 muito provavelmente decorrente do trauma. Assim, o paciente foi encaminhado para avaliação endodôntica para aplicação de hidróxido de cálcio e posterior penetração desinfectante ou tentativa de revascularização. 


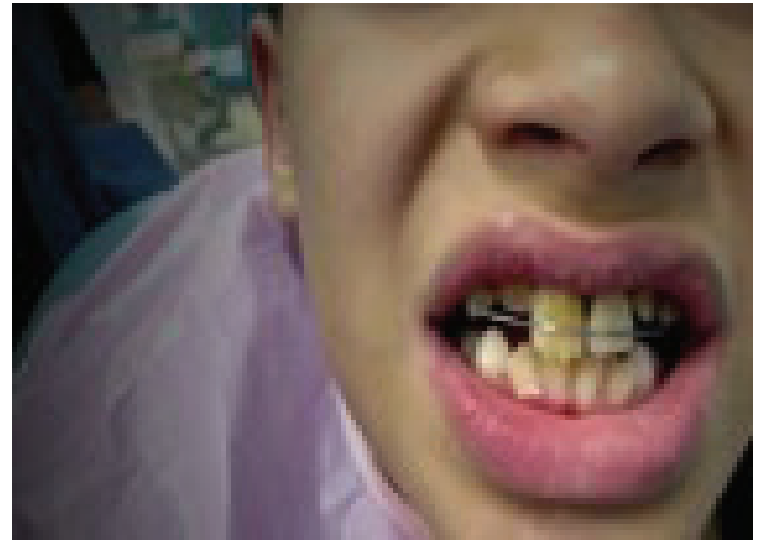

Figura 5 - Elemento 11 chegando à altura do provisório.

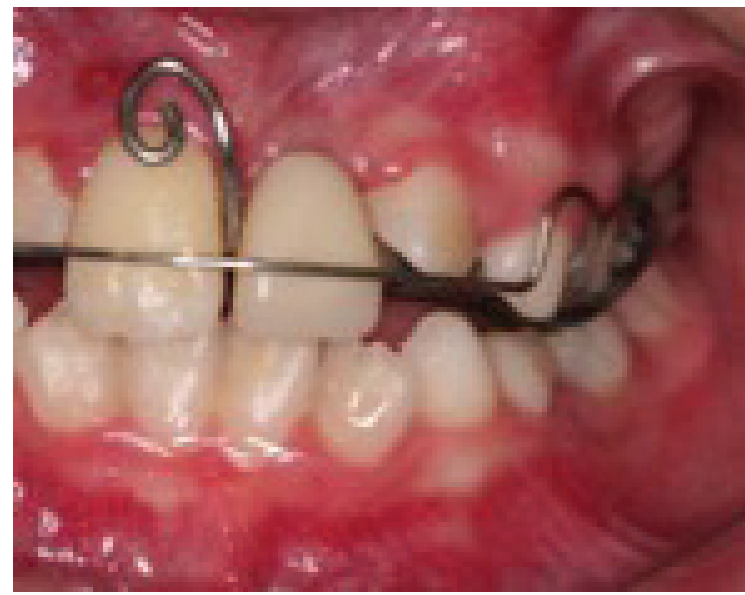

Figura 7 - Elemento 11 sem elástico.

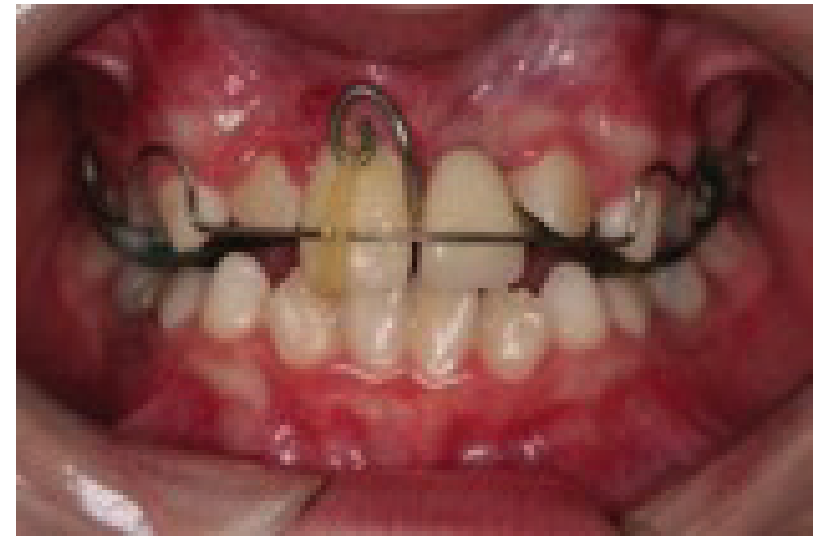

Figura 6 - Elemento 11 com elástico.

\section{DISCUSS ÃO}

A incidência de traumatismos dentários, vem aumentando e despertando o conhecimento na comunidade cientifica sobre essas lesões, principalmente em função do seu potencial para gerar alterações, de gravidade variada, como danos no ligamento periodontal e também na vascularização (que dá nutrição e oxigênio às células do dente). $\mathrm{O}$ dano é proporcional à intensidade, duração do trauma e estágio radicular causando possível necrose pulpar e infecção dos tecidos envolvidos ${ }^{1,8-9}$.

Dentre as lesões por traumatismo dentário, a avulsão dentária aparece numa prevalência que varia de 0,5 a 16\%3,5,17. A maior incidência das avulsões está associada aos incisivos centrais superiores permanentes, em crianças de 7 a 12 anos de idade (tabela 1), em razão das atividades da infância e da adolescência (tabela 2), favorecendo a exposição aos traumas dentais ${ }^{1,3,5,17}$.

Tabela 1. Idades mais acometidas pelo traumatismo dentário.

\begin{tabular}{c|c|c|c}
\hline Idade & $7-12$ anos & $13-19$ anos & $>20$ anos \\
\hline Porcentagem & $56,45 \%$ & $25,81 \%$ & $17,79 \%$ \\
\hline
\end{tabular}

Tabela 2. Principais causas dos acidentes que levam aos traumatismos dentários.

\begin{tabular}{l|c|c|c|c|c|c}
\hline $\begin{array}{l}\text { Causas dos } \\
\text { traumatismos }\end{array}$ & Quedas & $\begin{array}{l}\text { Acidentes } \\
\text { com } \\
\text { bicicleta }\end{array}$ & Atropelamento & $\begin{array}{l}\text { Causas } \\
\text { Indeterminadas }\end{array}$ & Agressões & $\begin{array}{l}\text { Acidentes } \\
\text { Automobilisticos }\end{array}$ \\
\hline Porcentagem & $45,59 \%$ & 0,1324 & $11,76 \%$ & $8,82 \%$ & $5,88 \%$ & $2,94 \%$ \\
\hline
\end{tabular}


Em uma análise, os resultados mostraram que a avulsão corresponde a 11,64\% dos casos de traumatismos alvéolo-dentários. Um estudo sobre a prevalência do traumatismo alvéolo dentário com relação ao gênero mostrou que os meninos são acometidos de aproximadamente duas vezes mais que as meninas - 30 e $16.1 \%$, respectivamente ${ }^{17}$.

No caso de dentes avulsionados com rizogênese completa e permanecidos em um meio seco extraoral por um período superior a 60 minutos, o tratamento de escolha consiste na remoção do ligamento periodontal e tratamento da superfície radicular por meio de substâncias químicas, antes do reimplante ${ }^{4,11,13-14}$.

O tratamento endodôntico extraoral é o adequado, pois o paciente não será submetido a procedimentos adicionais, tais como: radiografias, anestesia, dentre outros.

Em dentes com rizogênese incompleta com período de permanência no meio extraoral inferior a 60 minutos, poderá ocorrer o processo de revascularização pulpar. A imersão em uma solução com doxiciclina ( $1 \mathrm{mg} / 20 \mathrm{ml}$ de soro fisiológico) aplicada topicamente por 5 minutos antes do reimplante favorece essa revascularização ${ }^{13-14}$.

Todavia, o acompanhamento radiográfico por 3-4 semanas após o traumatismo poderá evidenciar alguma alteração patológica, devendo-se, nesse caso, iniciar o tratamento endodôntico ${ }^{13}$.

No Pronto Socorro Odontológico do Hospital Universitário Cajuru (PUCPR- Curitiba-Paraná), foi feita uma pesquisa sobre a frequência de avulsão dentária dentre os tipos de traumatismo dentário (tabela 3).

Tabela 3. Prevalência de traumatismos dentários no pronto socorro odontológico do hospital Cajuru, Curitiba, PR, Brasil:

\begin{tabular}{c|c|c|c|c|c|c|c}
\hline $\begin{array}{c}\text { Tipo de } \\
\text { Traumatismo }\end{array}$ & Avulsão & Intrusão & $\begin{array}{c}\text { Concussão e } \\
\text { subluxação }\end{array}$ & Extrusão & $\begin{array}{c}\text { Fraturas } \\
\text { coronárias }\end{array}$ & $\begin{array}{c}\text { Fraturas } \\
\text { Corono- } \\
\text { radiculares }\end{array}$ & $\begin{array}{c}\text { Fraturas } \\
\text { horizontais }\end{array}$ \\
\hline $\begin{array}{c}343 \text { Pacientes } \\
\text { Avaliados }\end{array}$ & $11,64 \%$ & $6,59 \%$ & $25,81 \%$ & $5,75 \%$ & $26,65 \%$ & $2,95 \%$ & $2,24 \%$ \\
\hline
\end{tabular}

O estudo no hospital, trata-se de um reflexo das pesquisas dos autores citados acima. A idade que é mais acometida é de 7- 9 anos (justificada pelas fibras serem menos rígidas, ou seja, rompem mais facilmente), afetando mais meninos (68\%) por quedas em esportes ${ }^{17}$.

A taxa de sucesso do reimplante dentário é em torno de 4 a $5 \%$, e uma das causas desse baixo índice é o desconhecimento do cirurgião-dentista perante a terapêtica indicada para cada caso individualmente ${ }^{9}$. A filosofia predominante para o tratamento eficaz tem sido reimplantar o dente o mais rápido possível depois da avulsão, de modo que se mantenha a vitalidade das células do ligamento periodontal ${ }^{9}$. Reimplantar um dente é um ato econômico, porém não depende apenas do conhecimento teórico e prático do cirurgião dentista, o sucesso está totalmente ligado à uma tríade: informação dos pais sobre como agir, forma de armazenamento adequada (SSBH) e o tempo de chegada $(<60$ min) ao consultório. Se alguma das "pontas" não for realizada, a chance do sucesso pode diminuir drasticamente. 


\section{CONCLUSÃO}

O tratamento realizado no relato de caso foi adequado, pois o dente reimplantado manteve-se na cavidade oral e foi corrigida a sua infra-oclusão contemplando a queixa principal do paciente.

\section{REFERÊNCIAS}

1. Andreasen JO, Andreasen FM. Texto e atlas colorido de traumatismo dental. Artmed; 2001.

2. Góes KKH, Ribeiro ED, Lima Júnior JL. Avaliando os traumatismos dentoalveolares: revisão de literatura. Rev Cir Traumatol Buco-Maxilo-Fac 2005;5(1):21-6.

3. Prata THC, Duarte MSR, Miquilito JL, Valera MC, Araújo MAM. Etiologia e frequência das injúrias dentárias traumáticas em pacientes do centro de traumatismos dentários da Faculdade de Odontologia de São José dos Campos - Unesp. Rev Odontol Unesp 2000;29(1/2):43-53

4. Soriano EP, Caldas Jr AF, Góes PSA. Risk factors related to traumatic dental injuries in Brazilian schoolchildren. Dent Traumatology 2004;20(5): 246-50.

5. Panzarini SR, Saad Neto M, Sonada CK, Poi WR, Carvalho ACP. Avulsões dentárias em pacientes jovens e adultos na região de Araçatuba. Rev da APCD 2003;57(1):27-31.

6. Lalloo R. Risk factors for major injuries to the face and teeth. Dent Traumatology 2003;19(1):12-4.

7. Traebert J, Almeida ICS, Gargheti C, Marcenes W. Prevalência, necessidade de tratamento e fatores predisponentes do traumatismo na dentição permanente de 11 a 13 anos de idade. Cad. Saúde Pública Rio de Janeiro 2004;20(2):403-10.

8. Ellis III E. Traumatismo dentoalveolar e aos tecidos moles. In: Peterson LJ et al. Cirurgia Oral e MaxiloFacial Contemporânea. $4^{\mathrm{a}}$ ed. Rio de Janeiro 2005; 535-58.

9. Westphalen VPD, Moraes IG, Westphalen FH. Reabsorção radicular: mecanismo e classificação. Rev Odonto Ciênc 2003;18(41):253-9.

10. Hiltz J, Trope M. Vitality of human lip fibroblasts in milk, Hank's balanced salt solution and ViaSpan storage media. Endod Dent Traumatol 1991;7(2):69-72.

11. Lee JY, Vann Júnior WF, Sigurdsson A. Management of avulsed permanent incisors:a decision analysis based on changing concepts. Am Academy Pediatric Dent - Pediatric Dent 2001;23(3):357-60.

12. Soares A, Nishiyama CK, Propowitsch I. Avaliação da preservação do ligamento periodontal em diferentes meios de conservação. Rev da APCD 2003; 57(2)):95-100.

13. Yanpiset K, Trope M. Pulp revascularization of replanted immature dog teeth afterdifferent treatment methods. Endod Dent Traumatol 2000; 16(5):211-7.

14. Trope M. Treatment of the avulsed tooth. Pediatric Dent 2000; 22(2):145-7.

15. Treatment of the avulsed permanent tooth: AAE publication. American Association of Endodontics 20041-6. Disponível em: http://www.aae.org/dentalpro/guidelines.htm

16. Schein MT, Isolan TMP. Esplinte funcional de dentes traumatizados. RBO1997;54(4):225-7.

17. Siviero AC, Westphalen VPD, Deonizio MDA. Prevalência de avulsões dentárias no Pronto-Socorro Odontológico do Hospital Cajuru. Rev de Clín Pesq Odontol 2005;1(3):48-50. 